\title{
Mission not yet completed: on the ups and downs of being the editor of ANP
}

\author{
Werner Paulus ${ }^{1}$
}

Received: 28 February 2019 / Accepted: 28 February 2019 / Published online: 5 March 2019

c) Springer-Verlag GmbH Germany, part of Springer Nature 2019

When I became the editor of this journal to succeed Kurt Jellinger in 2005, Acta Neuropathologica (ANP) was already a well-established and respected journal that had published some of the most influential papers in the field. From the beginning my goal was to combine excellent service and excellent science. The publisher has contributed by providing attractive features for authors, such as no page charges, free color figures, wide distribution with the great majority of institutions around the globe having full-text access, and fast, professional processing (copyediting, layout, publication) with mean times between accept and online publication of around 10 days. The mean time between submission and first editorial decision has also been around 10 days over the years (Fig. 1), and the journal has been able to publish particularly "hot" papers within 8 days following submission (!), including full reviews, revisions and copyediting. Many colleagues feel that ANP has among the shortest turnaround times, although unfortunately such data are not published or objectively compared among journals. Quality and relevance of published papers have increased during the years. Our clusters, collections of review articles included in regular issues and focussing on timely and interesting topics, have increased the journal's visibility and reputation, with the result that ANP has evolved as the natural forum for publishing the most important, relevant and topical original work. TDP-43, IDH, C9orf72, methylome-based tumor classification, chronic traumatic encephalopathy and many other breakthrough developments played a major role here. The impact factor (IF) has continuously increased in parallel with the number of submissions (Fig. 1). The current IF of 15.87 is by far the highest among all pathology journals publishing original papers, and among the 261 and 197 journals listed in the neuroscience and clinical neurology fields only

Werner Paulus

werner.paulus@uni-muenster.de

1 Institute of Neuropathology, University Hospital Münster, Pottkamp 2, 48149 Munster, Germany
Nature Neuroscience, Nature Reviews Neuroscience, Nature Reviews Neurology and Lancet Neurology have higher IFs.

Based on ANP's success and an increasing number of excellent papers that have had to be rejected for reasons of priority (whatever that is), I conceived, founded and edited our sister journal, Acta Neuropathologica Communications (ANC), in 2013 (from 2014 jointly with Johannes Attems). ANC has also become an excellent journal and received its first IF of 5.41 last year. The total number of pages published in ANP and ANC per year has tripled since 2005. Our regular author surveys have revealed that more than $90 \%$ of ANP authors have rated speed, fairness, technical quality, scientific quality and interaction with the editorial office as good or very good, and virtually all authors of published papers would like to publish again in this journal. Our ombudsman, Paul Kleihues, has been approached only once by a dissatisfied author in all these years, and this case was easily clarified. No single published paper has had to be retracted, in part because of the high standard of our reviewing process. Based on these data there can be little doubt that the journal has developed very well and that many people have been responsible for its great success. My sincere thanks go to the terrific editorial board, to the Münster editorial team (Fig. 2), and to all our referees and authors.

From a personal point of view, my relationship with ANP has been a wonderful emotional and cognitive experience. I became addicted to the editing and publishing process in 1989 when I worked with my mentor Kurt Jellinger in Vienna. Between obligations in neurology and neuropathology (Kurt was unique in heading both departments and in addition serving as an enthusiastic editor of ANP) I stepped into the editorial office and had the privilege of reading what the most prominent neuropathology referees at that time had to say about papers written by other prominent colleagues. I learned that any paper can be positively or negatively (re) viewed so that a judge is important. When I left Vienna, Kurt sent me packages with papers for review via postal mail. I eagerly awaited these packages, often including several 
Fig. 1 Bibliometric development (2004-2018): editorial turnaround time, number of submissions per year and impact factor issued in the same year

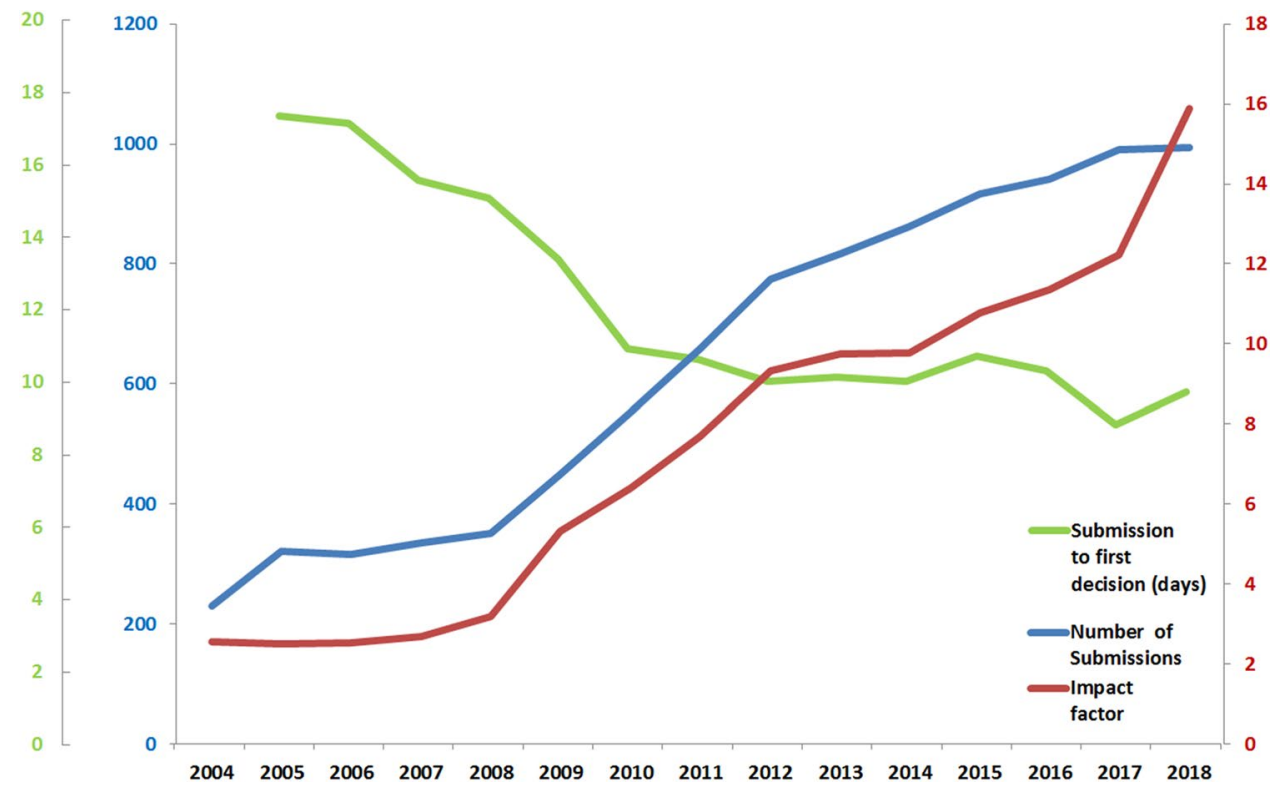

papers (sometimes the figures were lost because the envelope tended to be overfilled). Kurt invited me to join the editorial board in 1994, which made me very proud; at that time I had just completed my residency in Neuropathology and Pathology.

I always considered serving as editor of ANP to be a great privilege. I enjoyed working with the dedicated Editorial Board and receiving invaluable adviceI found it important that the Board be very active, hard-working, diverse, balanced and regenerating, rather than being merely a collection of big names as in so many other journals. I have always been impressed by the knowledge, insight, acumen and intellect of our referees who are working for free in anonymity, mainly for reasons of their enthusiasm for science. It was particularly fascinating to experience the personalities of so many eminent colleagues, just by reading through their reviews and mostly without having met them in person. Similarly, I appreciated the personalities of authors, facilitated in part by an increasing number of pre-submission enquiries and (unsolicited) rebuttal letters. It was remarkable and sometimes surprising to learn how neuropathology (and science in general) works in different nations. Because I have handled all submissions, except for cluster papers managed by another editor, I (should) have received the best possible education and a profound overview of virtually all areas of neuropathology. I have acquired a good feeling for topicality, quality, relevance, irrelevance and nonsense, which also required measures to counteract possible editorial dogmatism-and yes, I realize that these feelings are largely based on personal views, but at least I have tried to be consistent. I enjoyed the freedom of being an impartial judge, and I usually made editorial decisions based on my own reading of papers and reviews, rather than simply based on majority opinions of referees or by just inviting another referee in case of conflicting reviews (as is the case for most papers). Editing the leading journal in the field entails the possibility and necessity of shaping and, to some extent, redefining the field; this requires a high degree of responsibility and many challenging decisions. Successful shaping of a journal also requires effort and an insight that sitting and waiting for papers is not enough-identifying the most important and relevant topics and recruiting the best authors is required. Overall, editing a journal offers the fascinating and usually underestimated possibility of moving a field forward.

Unfortunately, there is also the dark side of the moon. Rejecting $85 \%$ of submissions is no fun, even though $15 \%$ of rejected submissions have found their way into ANC. Because most authors have invested considerable time, energy and enthusiasm in their papers, and because they often consider them as their scientific babies, many feel personally offended following rejection and consider the rejecting editor to be an ignorant idiot who does not understand quality and importance. Thus, editing a top journal and striving to maintain or increase quality does not make many friends. While I do not really have problems with being the bad guy, discussions have become somewhat laborious with time. On the other hand, most of the editor's work passes unnoticed in the community and by institutions. Most Universities provide acknowledgement and reward for publications, grants and teaching achievements, but not for editorial activities. Although in many other ways I receive considerable support from my University, I have not heard a word of appreciation from officials of my faculty for my work as editor of ANP, while they get excited when a member of the faculty has been able to publish a paper in this top journal. 
Fig. 2 Phenotypic development (2004-2019): while art (Claes Oldenburg's Giant Pool Balls near Münster's Lake Aa) and recreational utilization of the area have markedly evolved, the Münster editorial team appears relatively unchanged; decreased pigmentation reflects hard editorial work in the dark (from right to left: Martin Hasselblatt, Ralf Mersmann, Joachim Gerß, Werner Paulus)
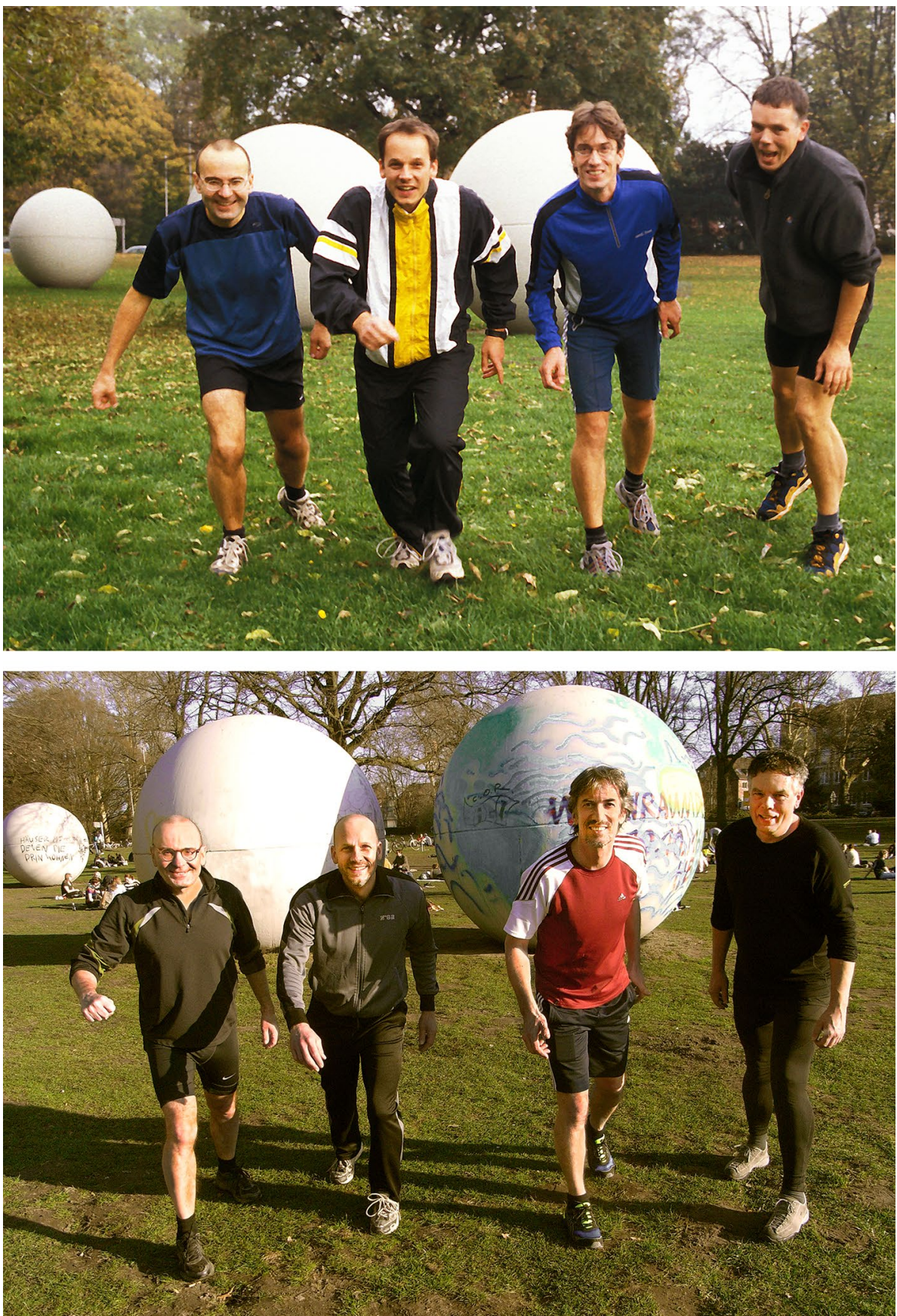

The higher the journal's IF climbed, the more I recognized that scientific publishing is like a market in which the "show" plays a considerable role in "selling" the product for the highest price/attention/IF possible, which has become somewhat unsettling for me. Common ingredients of the show include inventing a good story, following current trends with respect to diseases, genes and models, applying and over-rating methods that others do not have, some kind of data over-interpretation, citing the right papers, selecting the right coauthors, and flattering the editor. This is part of the business, but I was afraid that with time watching the show may destroy the wonderful idea that scientists primarily work to find the truth.

Working as an editor with a commercial publisher has a number of advantages and poses serious challenges. On the one hand, the extensive experience of publishers with layout, production and promotion facilitates the work of editors. On the other hand, a publisher who owns the journal has the right to decide on many issues that may be opposed to the interests of editors, including the number of journal pages to be published per year, content and design of the journal website, article processing and subscription fees, formal 
requirements for papers, the increasing number of disclosures and statements that are requested from authors, and even the content on the editor's social media channels such as twitter. The publisher's aim of making the most profit and the editor's aim of publishing the most interesting and most important science are not always compatible. For example, publishers tend to homogenize the appearance of all the journals in their portfolio, while editors' requests for special features in their individual journals are either impossible to fulfill or can only be achieved after tough negotiations. I thank SpringerNature for the insight into the mechanisms of the publication process that I received during my time as editor. It showed me, for example, that scientists tend to believe (and commercial publishers make them believe) that the publication process requires huge amounts of money and that this money must come from either authors (article processing fees) or readers (subscription fees), while I have come to the conclusion that neither of these statements is true.

Finally, I have to admit that passionate editing takes time, several hours every day, 365 days a year, for identifying the perfect referees via searching PubMed, Google and institutional websites, reading through papers, revised versions and rebuttals, making difficult editorial decisions, rating reviews, checking proofs, thinking about new clusters and interesting review papers, working with authors and referees, discussions with the publisher on modernizing the website and software for handling manuscripts, investigating claims of scientific fraud, building journal issues, designing the monthly artistic covers together with Ralf Mersmann (oldfashioned but fun), evaluating author surveys, doing statistics on this and that, and trying to improve everything. All this time-consuming stuff probably had negative effects on my Hirsch index and my research funding, and it has reduced my free time for personal activities and my family. I am not complaining at all. Life is a matter of priorities and decisions, everything has its time in life, and in retrospect I am more than happy with my decision to have served as editor of ANP for such a long time.

Prominent examples from sport and politics have demonstrated that finding the right time for stepping down is often difficult. While I leave as editor with mixed feelings, I believe that the timing is good, in part because the perfect successor is ready to start. Johannes Attems and I have coedited ANC for 5 years and we share similar views concerning the scope of the journals and our dedication to excellent science and excellent service. Johannes has also trained with Kurt Jellinger and he has adopted Kurt's proclivity for clinical relevance. As for me, I will try to follow in Kurt's footsteps once again. He has been an excellent senior editor for the past 14 years: always providing advice if asked, always having a word of encouragement, being open-minded and excited by positive developments and success of the journal, and never exhibiting the attitude of knowing something better. All the best to our good old Acta-I am sure you will thrive under Johannes' leadership. 